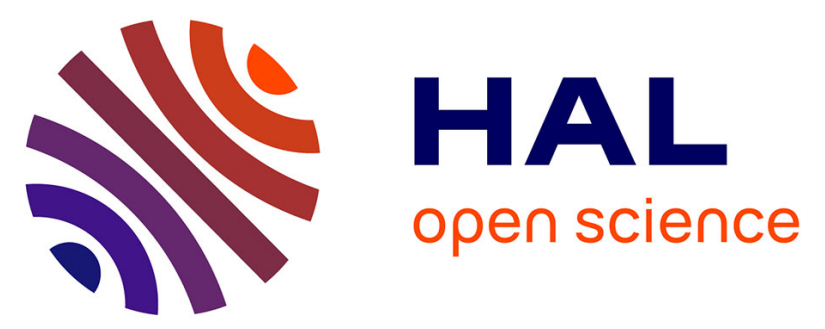

\title{
Zinc isotopes in HEDs: clues to the formation of 4-Vesta, and the unique composition of Pecora Escarpment 82502
}

Randal Paniello, Frédéric Moynier, Pierre Beck, Jean-Alix J-A Barrat, Frank Podosek, Sylvain Pichat

\section{- To cite this version:}

Randal Paniello, Frédéric Moynier, Pierre Beck, Jean-Alix J-A Barrat, Frank Podosek, et al.. Zinc isotopes in HEDs: clues to the formation of 4-Vesta, and the unique composition of Pecora Escarpment 82502. Geochimica et Cosmochimica Acta, 2012, 86, pp.76-87. 10.1016/j.gca.2012.01.045 . insu00670085

\section{HAL Id: insu-00670085}

\section{https://hal-insu.archives-ouvertes.fr/insu-00670085}

Submitted on 25 Feb 2013

HAL is a multi-disciplinary open access archive for the deposit and dissemination of scientific research documents, whether they are published or not. The documents may come from teaching and research institutions in France or abroad, or from public or private research centers.
L'archive ouverte pluridisciplinaire HAL, est destinée au dépôt et à la diffusion de documents scientifiques de niveau recherche, publiés ou non, émanant des établissements d'enseignement et de recherche français ou étrangers, des laboratoires publics ou privés. 


\title{
Zinc isotopes in HEDs: Clues to the formation of 4-Vesta, and the unique composition of Pecora Escarpment 82502
}

\author{
Randal C. Paniello ${ }^{\mathrm{a}, *}$, Frédéric Moynier ${ }^{\mathrm{a}}$, Pierre Beck ${ }^{\mathrm{b}}$, Jean-Alix Barrat ${ }^{\mathrm{c}}$, \\ Frank A. Podosek ${ }^{a}$, Sylvain Pichat ${ }^{\mathrm{d}}$ \\ a Department of Earth and Planetary Sciences and McDonnell Center for Space Sciences, Washington University in St. Louis, \\ One Brookings Drive, St. Louis, MO 63130, United States \\ ${ }^{\mathrm{b}}$ Laboratoire de Planetologie, Université Joseph Fourier, Grenoble, France \\ ${ }^{\mathrm{c}}$ Université Européenne de Bretagne et Université de Brest, I.U.E.M., CNRS UMR 6538 (Domaines Océaniques), \\ Place Nicolas Copernic, 29280 Plouzané Cedex, France \\ ${ }^{\mathrm{d}}$ Ecole Normale Superieure de Lyon, France
}

Received 22 November 2010; accepted in revised form 31 January 2012; available online 11 February 2012

\begin{abstract}
The $\delta^{66} \mathrm{Zn}$ (permil deviation of the ${ }^{66} \mathrm{Zn} /{ }^{64} \mathrm{Zn}$ ratio from a terrestrial standard) values for a suite of 20 non-Antarctic HED (howardite-eucrite-diogenite) meteorites and one mesosiderite, and for eight Antarctic eucrites and diogenites, were measured in order to determine the role of volatization in the formation of their presumed parent body, the asteroid 4 -Vesta. The 20 non-Antarctic HEDs had $\delta^{66} \mathrm{Zn}$ values that ranged from $-2.0 \%$ to $+1.67 \%$, with a mean value of $-0.01 \pm 0.39 \%$ ( 2 se); this range likely represents a small-scale heterogeneity due to brecciation induced by multiple impacts. The non-Antarctic eucrites $\left(\delta^{66} \mathrm{Zn}=+0.00 \pm 0.58 \%\right.$ ( $\left.\left.2 \mathrm{se}\right), n=12\right)$ were isotopically the same as the diogenites $\left(\delta^{66} \mathrm{Zn}=-0.31 \pm 0.80 \%(2 \mathrm{se}), n=4\right)$, and the howardites $\left(\delta^{66} \mathrm{Zn}=+0.26 \pm 0.37 \%\right.$ ( $\left.\left.2 \mathrm{se}\right), n=4\right)$. On average, non-Antarctic eucrite falls were isotopically heavier $(+0.50 \%)$ than non-Antarctic finds $(-1.00 \%)$. The Antarctic finds studied were all unbrecciated samples, and they were significantly heavier than the non-Antarctic samples with a $\delta^{66} \mathrm{Zn}$ range of $+1.63 \%$ to $+6.22 \%$ for four eucrites (mean, $+4.32 \%$ ) and $+0.94 \%$ to $+1.60 \%$ for three diogenites (mean $+1.23 \%$ ), excluding one anomalous sample, while their $\mathrm{Zn}$ concentration is significantly lower than the brecciated samples. These data suggest that the unbrecciated eucrites probably represent the eucritic crust shortly after differentiation and cooling of the parent asteroid, at which time volatization of lighter zinc isotopes led to an isotopically heavy crust. Early impact events caused the ejection of these unbrecciated meteorites, which were subsequently spared from brecciation caused by multiple additional impacts on the much larger Vesta. The range of $\delta^{66} \mathrm{Zn}$ values and $\mathrm{Zn}$ concentration for the brecciated HEDs in this study supports a major contribution to the Vestan surface by chondritic impactors $\left(-1.30<\delta^{66} \mathrm{Zn}<+0.76 \%\right.$ for ordinary and carbonaceous chondrites). The anomalous eucrite PCA 82502 $\left(\delta^{66} \mathrm{Zn}=-7.75 \%\right)$ is significantly isotopically lighter than the other HEDs and is the natural sample with the lightest $\mathrm{Zn}$ isotopic composition reported in the solar system to date. This meteorite most likely originated from a distinct parent body. (c) 2012 Elsevier Ltd. All rights reserved.
\end{abstract}

\section{INTRODUCTION}

The HED meteorites (howardites, eucrites, and diogenites) comprise the largest group of achondrites, and are

\footnotetext{
* Corresponding author.

E-mail address: paniellor@ent.wustl.edu (R.C. Paniello).
}

generally agreed to have originated from asteroid 4 Vesta based on visible and near-infrared reflectance spectrographic similarities (e.g., McCord et al., 1970; Binzel and $\mathrm{Xu}, 1993$; Burbine et al., 2001). With a few exceptions (Scott et al., 2009a), they share the same $\Delta^{17} \mathrm{O}$ ratios that distinguish them from the Earth or the Moon (Clayton and Mayeda, 1996; Greenwood et al., 2005). Most eucrites are pigeonite-plagioclase basalts, most diogenites are 
orthopyroxenites, and howardites are mechanical mixtures of these (with some exceptions; see Warren et al. (2009)). Almost all of the HED meteorites are breccias, implying significant "gardening" occurred after their initial formation due to multiple impacts on the parent body. Mesosiderites are stony-iron meteorites with about equal parts metal (nickel-iron) and silicates that are similar in composition to HEDs. They have an oxygen isotope composition that is indistinguishable from the HEDs and may also have originated from Vesta (Greenwood et al., 2006).

Studies of major elements and rare earth elements in HED meteorites have led to different theories of formation and differentiation of 4 Vesta. In one model (Takeda, 1979), the asteroid is initially totally melted; then, differentiation led to a metallic core surrounded by a magma ocean. A fractional crystallization sequence then proceeded to form orthopyroxenites (diogenites), followed by increasing plagioclase content to form basalts (eucrites). Since the eucrites formed last in this model from the remaining melt, it is sometimes called the "residual liquid" model of eucrite petrogenesis (e.g., Warren, 1997). Alternatively, the original parent body formed and cooled, then underwent heating events that caused primary partial melts (Stolper, 1977). In this model, total melting would not be expected. Over the last 30 years a number of additional models have been proposed that are basically variants of these (e.g., Warren and Jerde, 1987; Hewins and Newsom, 1988; Righter and Drake, 1997; Ruzicka et al., 1997; Warren, 1997; Mittlefehldt and Lindstrom, 2003; Greenwood et al., 2005), however, consensus on a single model of HED petrogenesis has been elusive.

Recent petrological studies suggest that the magmatic history of Vesta was certainly much more complex than previously thought. Firstly, a magma ocean model cannot account for the diversity of the REE patterns displayed by the diogenites and their pyroxenes (e.g., Mittlefehldt, 1994; Shearer et al., 1997), and diogenites could have formed from melts produced by the remelting of magma ocean cumulates (Barrat, 2004; Barrat et al., 2008, 2009a). Secondly, the eucritic crust was probably remelted, producing new melts able to contaminate not only normal eucrites (e.g., Barrat et al., 2007; Yamaguchi et al., 2009) but also some of the parental melts of diogenites (Barrat et al., 2010). Finally, K-rich impact spherules in howardites indicate that the lithologies exposed on the surface of Vesta are not restricted to eucrites and diogenites, and point to some distinct K-rich areas (Barrat et al., 2009b).

Vesta shows spectroscopic evidence of differentiation by igneous processes (Binzel and Xu, 1993), which most likely led to a layered structure with a crust chiefly eucritic, an ultramafic mantle, and a metallic core (e.g., Righter and Drake, 1997). Most eucrites show evidence of metamorphism with reheating to $>800{ }^{\circ} \mathrm{C}$, as evidenced by altered pyroxene compositions from subsolidus diffusion of $\mathrm{Mg}$, Fe and Ca (Takeda and Graham, 1991; Yamaguchi et al., 1996, 1997, 2009). The source of this additional heat may have been from large impacts (Nyquist et al., 1986), heating at depth after burial of surface basalts (Yamaguchi et al., 1996, 1997), or the differentiation into layers (Takeda, 1997). A large impact crater of $460 \mathrm{~km}$ diameter, $13 \mathrm{~km}$ depth with a large central peak, has been identified on Vesta
(Thomas et al., 1997) which may have extended beyond the crust into the mantle layer and ejected many Vestoids and HEDs (McSween et al., 2010). The age of this impact crater is controversial, with some evidence suggesting it occurred during the Late Heavy Bombardment period of 3.5-4.0 billion years ago (Scott et al., 2009b), and other evidence supporting an age of only 1 billion years (Asphaug, 1997). Ejecta from this large impact, possibly including samples of the deep asteroidal crust and mantle, may now be present on the surface of 4-Vesta.

Compared with chondritic meteorites, HEDs show large depletions in moderately volatile elements, $\mathrm{Zn}$ being one of the best examples. Zinc is present in very low concentrations $([\mathrm{Zn}]<7 \mathrm{ppm})$ in all three HED groups (e.g., Barrat et al., 2000, 2007; Kitts and Lodders, 1998) with most diogenites less than 1 ppm (Barrat et al., 2008); this is lower than the zinc level found on larger planetary bodies such as the Moon, the Earth, or Mars (2-20, 50 and 90 ppm, respectively; Lodders and Fegley, 1998; Wolf et al., 2009) and chondrite meteorites (40-300 ppm, Lodders and Fegley, 1998). The mechanism by which the moderately volatile elements were depleted from HEDs is still debated. Volatilization is known to fractionate isotopes, thus comparing the isotope compositions of volatile elements between HEDs and other meteorites may help to understand the physical and chemical conditions involved in the loss of volatile elements.

Zinc is a moderately volatile element with a $50 \%$ condensation temperature, $T_{\mathrm{c}}(\mathrm{Zn})$, of $\sim 730 \mathrm{~K}$ (Lodders, 2003) and seems to be even more volatile under conditions relevant to the metamorphism of ordinary chondrites (Schaefer and Fegley, 2010). Measurements of $\mathrm{Zn}$ isotopes in a variety of terrestrial magmatic materials show a remarkably homogeneous distribution, with ${ }^{66} \mathrm{Zn} /{ }^{64} \mathrm{Zn}$ ratios consistently within 0.2 permil of each other (Ben Othman et al., 2006). This suggests that within the Earth's mantle, $\mathrm{Zn}$ isotopes are well mixed and homogeneously distributed, and that igneous processes do not result in significant $\mathrm{Zn}$ isotopic fractionation (Ben Othman et al., 2006).

In this study, we used $\mathrm{Zn}$ isotopic measurements to investigate possible formation mechanisms of the HED parent body 4-Vesta. Previous studies have demonstrated the utility of $\mathrm{Zn}$ isotopes for this purpose. $\mathrm{Zn}$ isotopic determinations in chondrites and iron meteorites show significantly more variation than is found in terrestrial materials (Luck et al., 2005; Moynier et al., 2007; Barrat et al., 2012), suggesting volatilization processes and core/mantle segregation in their formation. On the Earth and on the Moon, volatization from impact events is the primary cause of $\mathrm{Zn}$ isotopic fractionation (Moynier et al., 2006, 2009, 2010; Albarède et al., 2007; Herzog et al., 2009). We have previously used $\mathrm{Zn}$ isotope ratios to determine the role of impact-induced volatization in the formation of tektites (Moynier et al., 2009) and ureilites (Moynier et al., 2010). Thus, the study of $\mathrm{Zn}$ isotopes in extraterrestrial samples can provide clues to their mechanisms of formation (Luck et al., 2005), especially as they relate to evaporation/condensation processes (Moynier et al., 2006). Here, we used zinc isotopic composition in HEDs to assess the role of volatization processes in the formation of 4-Vesta. 
Due to its very low abundance in HEDs, the analysis of zinc isotopic composition requires a highly sensitive technique. In this study, HED meteorites were analyzed for $\mathrm{Zn}$ isotopic composition using Multi Collector-Inductively Coupled Plasma-Mass Spectrometry (MC-ICP-MS).

\section{SAMPLES AND ANALYTICAL METHODS}

\subsection{Sample description}

The $\mathrm{Zn}$ isotopic compositions of 43 samples from 28 HED meteorites, and one mesosiderite, were measured. There were 23 chips from 17 eucrites, six chips from four howardites, and eight chips from seven diogenites analyzed. In five cases, multiple chips were created from a single museum sample by fracturing it into two or more smaller chips, which were then processed separately (dissolutionchemical separation of $\mathrm{Zn}$ and mass-spectrometry analysis) on different dates. Among the eucrite samples, Pasamonte and PCA 82502 are unusual samples with $\Delta^{17} \mathrm{O}$ plotting outside the HED range (Greenwood et al., 2009). In addition, to study the sample heterogeneity, three clasts and two matrix samples prepared from 'large' aliquots $(>2 \mathrm{~g}$ each time, Barrat et al., 2003) of the eucrite Juvinas were analyzed.

Seventeen of the meteorites were falls, twelve were finds. Most of the eucrites were monomict breccias. The Antarctic finds (five eucrites and three diogenites) were all unbrecciated, as was one diogenite fall (Tatahouine). The sample descriptions are summarized in Table 1.

To better constrain the terrestrial isotopic composition of $\mathrm{Zn}$, the isotopic composition of two terrestrial igneous geostandards GIT-IWG BE-N (a terrestrial basalt from Essey-la-Côte, France) and USGS G-2 (a terrestrial granite) were analyzed as well.

\subsection{Methods}

All sample processing was performed in a "clean room" in order to minimize any possible contamination. Each meteorite chip was 75-500 mg in order to extract enough zinc for analysis, the mass chosen was based on anticipated $\mathrm{Zn}$ concentrations from published studies. Fusion crust, if present, was gently removed; the chip was fractured into multiple small pieces, and then those with fusion crust were hand-picked and separated. Chips were cleansed in water in an ultrasonic bath, then crushed in an agate mortar into a homogenous powder. The powder was dissolved in $\mathrm{HNO}_{3} /$ $\mathrm{HF}$ in closed Teflon beakers at $\sim 120^{\circ} \mathrm{C}$ for 2 days. A final step of dissolution in $6 \mathrm{~N} \mathrm{HCl}$ was done in order to re-dissolve the fluorides formed by the HF. All reagents used were of the highest available purity.

The procedure described by Moynier et al. (2006) was used to extract and purify the zinc from the samples. The dissolved solute was evaporated under a heating lamp, and the residue was re-dissolved in $1.5 \mathrm{~N} \mathrm{HBr}$. Teflon columns were prepared for anion-exchange chromatography by loading with AG-1X8 (200-400 mesh), cleaning with $0.5 \mathrm{~N} \mathrm{HNO}_{3}$, and then pre-loading with $1.5 \mathrm{~N} \mathrm{HBr}$. Each sample was loaded onto a column, and the $\mathrm{Zn}$ bound to the mesh while the remaining non- $\mathrm{Zn}$ components passed through the column with additional $1.5 \mathrm{~N} \mathrm{HBr}$. The $\mathrm{Zn}$ was then recovered from the column with $0.5 \mathrm{~N} \mathrm{HNO}_{3}$. The entire process was repeated twice more on smaller columns to further purify $\mathrm{Zn}$ from impurities. Column fractionation of $\mathrm{Zn}$ was avoided by near-complete $(>99 \%)$ recovery of the $\mathrm{Zn}$. The final $\mathrm{Zn}$ eluent was evaporated, then redissolved in $0.05 \mathrm{~N} \mathrm{HNO}_{3}$ for isotopic compositional analysis by MC-ICP-MS.

Zinc isotopic compositions were measured on a Nu Plasma High Resolution MC-ICP-MS at the Ecole Normale Superieure de Lyon, France, or on a Thermo-Finnigan Neptune Plus MC-ICP-MS at Washington University, St. Louis, following the procedure described in Maréchal et al. (1999). Both instruments are high-resolution MCICP-MS and routinely provide similar quality $\mathrm{Zn}$ stable isotopic data. For both machines, the yield was found to be greater than $99 \%$ and the blank was $\sim 10 \mathrm{ng}$. Isotope ratios are expressed as parts per 1000 deviations relative to a standard:

$\delta^{\mathrm{x}} \mathrm{Zn}(\%)=\left(\frac{\left({ }^{\mathrm{x}} \mathrm{Zn} /{ }^{64} \mathrm{Zn}\right)_{\text {sample }}}{\left({ }^{\mathrm{x}} \mathrm{Zn} /{ }^{64} \mathrm{Zn}\right)_{\text {standard }}}-1\right) \times 1000$

with $x=66$ or 68 . The reference material used is the $\mathrm{Zn}$ "Lyon" standard JMC 3-0749 L (Maréchal et al. 1999). The "Lyon" standard is the most broadly used reference material to normalize $\mathrm{Zn}$ isotope data (reviewed in Albarède, 2004). At least two replicate analyses were performed for $80 \%$ of the samples; 3-6 replicates were performed for the more extreme samples such as PCA 82502. The replicate analyses of the same samples carried out during different analytical sessions define an external reproducibility ( $\pm 2 \mathrm{sd}$ ) of $\pm 0.09 \%$ for $\delta^{66} \mathrm{Zn}$ and $\pm 0.27 \%$ for $\delta^{68} \mathrm{Zn}$ (see Moynier et al. (2006) and Herzog et al. (2009) for extensive discussion of our analytical precision). With respect to the total amount of $\mathrm{Zn}$ in the samples, the blank of about $10 \mathrm{ng}$ introduces an error of $0.10 \%$ or less, based on a "worst case" contaminant of $\delta^{66} \mathrm{Zn}=-2.0 \%$ added to the smallest $\mathrm{Zn}$ content sample $(\mathrm{Zn}=290 \mathrm{ng})$ at a presumed $+1.0 \%$ (thus the blank is $3.4 \%$ or less of the sample). We note that there are no known potential terrestrial contaminants with a $\delta^{66} \mathrm{Zn}$ below zero, so this is a highly conservative estimate.

Elemental concentrations of $\mathrm{Zn}$ were calculated by comparing the voltage peak heights of ${ }^{64} \mathrm{Zn}$ with peak heights for known standards. In most cases the unknown concentrations were adjusted so as to be within $\pm 10 \%$ of the standard concentrations. No systematic dependence of isotopic abundances on solution concentration was observed. Uncertainties in concentrations were about $\pm 10 \%$.

\section{RESULTS}

The measurements of $\delta^{66} \mathrm{Zn}$ and $\delta^{68} \mathrm{Zn}$ for all of the samples are given in Table 1, and plotted in Fig. 1. All data plot on the mass-dependent fractionation line of slope 1.978 $\left(R^{2}=0.9993\right)$ on the three-isotope plot. All of the non-Antarctic HED $\delta^{66} \mathrm{Zn}$ values lie within $0 \pm 2 \%$, The HED subgroup ranges overlap significantly: non-Antarctic 
Table 1

Zinc isotope measurements for HED meteorites and terrestrial standards.

\begin{tabular}{|c|c|c|c|c|c|c|c|c|}
\hline Class & Name & Split & Type & $f / f$ & $\begin{array}{l}\delta^{66} \mathrm{Zn} \\
(\%) \\
\end{array}$ & $\begin{array}{l}\delta^{68} \mathrm{Zn} \\
(\%) \\
\end{array}$ & $\begin{array}{l}{[\mathrm{Zn}]} \\
(\mathrm{ppm}) \\
\end{array}$ & $\begin{array}{l}\text { Mass } \\
(\mathrm{mg}) \\
\end{array}$ \\
\hline \multicolumn{9}{|l|}{ Eucrites } \\
\hline \multirow[t]{23}{*}{ Falls } & Béréba & MNHN 1297CPE & $\mathrm{mm}$ & Fall & 1.67 & 3.40 & 1.30 & 242 \\
\hline & Jonzac & NMV A419 & $\mathrm{mm}$ & Fall & 0.33 & 0.74 & 1.40 & 460 \\
\hline & Juvinas & MNHN 40PE2 & $\mathrm{mm}$ & Fall & 0.06 & 0.17 & 2.50 & 300 \\
\hline & Matrix 1 & MNHN & $\mathrm{mm}$ & Fall & 0.30 & 0.72 & 2.30 & $\sim 2000$ \\
\hline & Matrix 2 & MNHN & $\mathrm{mm}$ & Fall & 0.37 & 0.86 & 0.70 & $\sim 2000$ \\
\hline & Clast 1 & MNHN & $\mathrm{mm}$ & Fall & 0.39 & 1.02 & 1.50 & $\sim 2000$ \\
\hline & Clast 2 & MNHN & $\mathrm{mm}$ & Fall & 0.57 & 1.22 & 2.90 & $\sim 2000$ \\
\hline & Clast 3 & MNHN & $\mathrm{mm}$ & Fall & 0.31 & 0.85 & 1.20 & $\sim 2000$ \\
\hline & Mean-Juvinas & & & & 0.33 & 0.81 & & \\
\hline & Millbillillie & WAM 13357.3 & $\mathrm{~mm}$ & Fall & -0.79 & -1.37 & 0.90 & 323 \\
\hline & Pasamonte chip 1 & ASU $197 \mathrm{~g}$ & $\mathrm{pm}$ & Fall & 0.05 & 0.14 & 6.70 & 813 \\
\hline & Pasamonte chip 2 & ASU $197 \mathrm{~g}$ & $\mathrm{pm}$ & Fall & -0.81 & -1.58 & 8.90 & 320 \\
\hline & Pasamonte chip 3 & USNM 897 & $\mathrm{pm}$ & Fall & 1.35 & 2.57 & 2.10 & 975 \\
\hline & Mean-Pasamonte & & & & 0.20 & 0.38 & & \\
\hline & Serra de Magé & MNHN 1560PE & $\mathrm{cm}$ & Fall & 0.62 & 1.28 & 0.78 & 296 \\
\hline & Sioux County chip 1 & NHM BM.1959,1029 & $\mathrm{mm}$ & Fall & 1.11 & 2.41 & 1.30 & 249 \\
\hline & Sioux County chip 2 & NHM BM.1959,1029 & $\mathrm{mm}$ & Fall & 0.90 & 1.88 & 0.80 & 437 \\
\hline & Sioux County chip 3 & ASU 198.3 & $\mathrm{~mm}$ & Fall & -0.73 & -1.49 & 0.90 & 346 \\
\hline & Mean - Sioux County & & & & 0.43 & 0.93 & & \\
\hline & Stannern chip 1 & NMV & $\mathrm{mm}$ & Fall & 1.42 & 2.90 & 1.00 & 334 \\
\hline & Stannern chip 2 & MNHN 4027PE1 & $\mathrm{mm}$ & Fall & 0.95 & 2.05 & 7.80 & 290 \\
\hline & Mean - Stannern & & & & 1.19 & 2.48 & & \\
\hline & Mean - Eucrite falls $(n=8)$ & & & & 0.50 & 1.08 & & \\
\hline \multicolumn{9}{|l|}{ Finds } \\
\hline \multirow{5}{*}{ Non-Antarctic } & Bouvante & MNHN 3223PE & $\mathrm{mm}$ & Find & -1.76 & -3.33 & 5.00 & 235 \\
\hline & Camel Donga & WAM 13715 & $\mathrm{~mm}$ & Find & -0.30 & -0.26 & 0.90 & 356 \\
\hline & Palo Blanco Creek & UNM & $\mathrm{mm}$ & Find & -1.49 & -2.70 & 2.30 & 396 \\
\hline & Pomozdino & & $\mathrm{mm}$ & Find & -0.43 & -0.65 & 4.50 & 72 \\
\hline & Mean-Non-Antarctic Eucri & finds $(n=4)$ & & & -1.00 & -1.74 & & \\
\hline \multirow[t]{10}{*}{ Antarctic } & PCA 82502 & NASA, .97 & unbr & Find & -7.75 & -15.14 & 4.50 & 414 \\
\hline & GRA 98098 chip 1 & NASA, .55 & unbr & Find & 5.84 & 11.75 & 0.46 & 530 \\
\hline & GRA 98098 chip 2 & NASA, .55 & unbr & Find & 6.29 & 12.54 & 0.39 & 470 \\
\hline & Mean - GRA 98098 & & & & 6.06 & 12.15 & 0.42 & \\
\hline & QUE 97014 & NASA, .31 & unbr & Find & 1.63 & 3.33 & 0.69 & 557 \\
\hline & BTN 00300 & NASA, .13 & unbr & Find & 3.32 & 7.12 & 0.11 & 575 \\
\hline & EET 90020 & NASA, .51 & unbr & Find & 6.22 & 12.45 & 0.16 & 611 \\
\hline & Mean - Antarctic Eucrite & $d s(n=4)^{*}$ & & & 4.31 & 8.76 & & \\
\hline & Mean - All Eucrite finds & $=8)^{*}$ & & & 1.66 & 3.51 & & \\
\hline & Mean - All non-Antarctic & icrites $(n=12)^{*}$ & & & 0.00 & 0.14 & & \\
\hline \multirow{2}{*}{\multicolumn{3}{|c|}{ Mean - All Eucrites $(n=16)^{*} \pm 2 S E$}} & & & 1.08 & 2.30 & & \\
\hline & & & & & 1.17 & 2.32 & & \\
\hline \multirow[t]{10}{*}{ Howardites } & Kapoeta chip 1 & NHM BM.1946,141 & $\mathrm{pm}$ & Fall & -0.43 & -0.68 & 1.90 & 169 \\
\hline & Kapoeta chip 2 & NHM BM.1946,141 & $\mathrm{pm}$ & Fall & 0.38 & 0.77 & 8.00 & 546 \\
\hline & Mean-Kapoeta & & & & -0.03 & 0.05 & & \\
\hline & LeTeilleul & MNHN 711PE & $\mathrm{pm}$ & Fall & 0.09 & 0.21 & 3.00 & 218 \\
\hline & Pavlovka chip 1 & MNHN 2698PE & $\mathrm{pm}$ & Fall & 0.22 & 0.63 & 3.00 & 261 \\
\hline & Pavlovka chip 2 & MNHN 2698PE & $\mathrm{pm}$ & Fall & 1.38 & 3.04 & 4.50 & 77 \\
\hline & Mean-Pavlovka & & & & 0.80 & 1.84 & & \\
\hline & Petersburg & & $\mathrm{pm}$ & Fall & 0.16 & 0.38 & 1.20 & 511 \\
\hline & wardites $(n=4) \pm 2 S E$ & & & & 0.26 & 0.62 & & \\
\hline & & & & & 0.37 & 0.82 & & \\
\hline
\end{tabular}


Table 1 (continued)

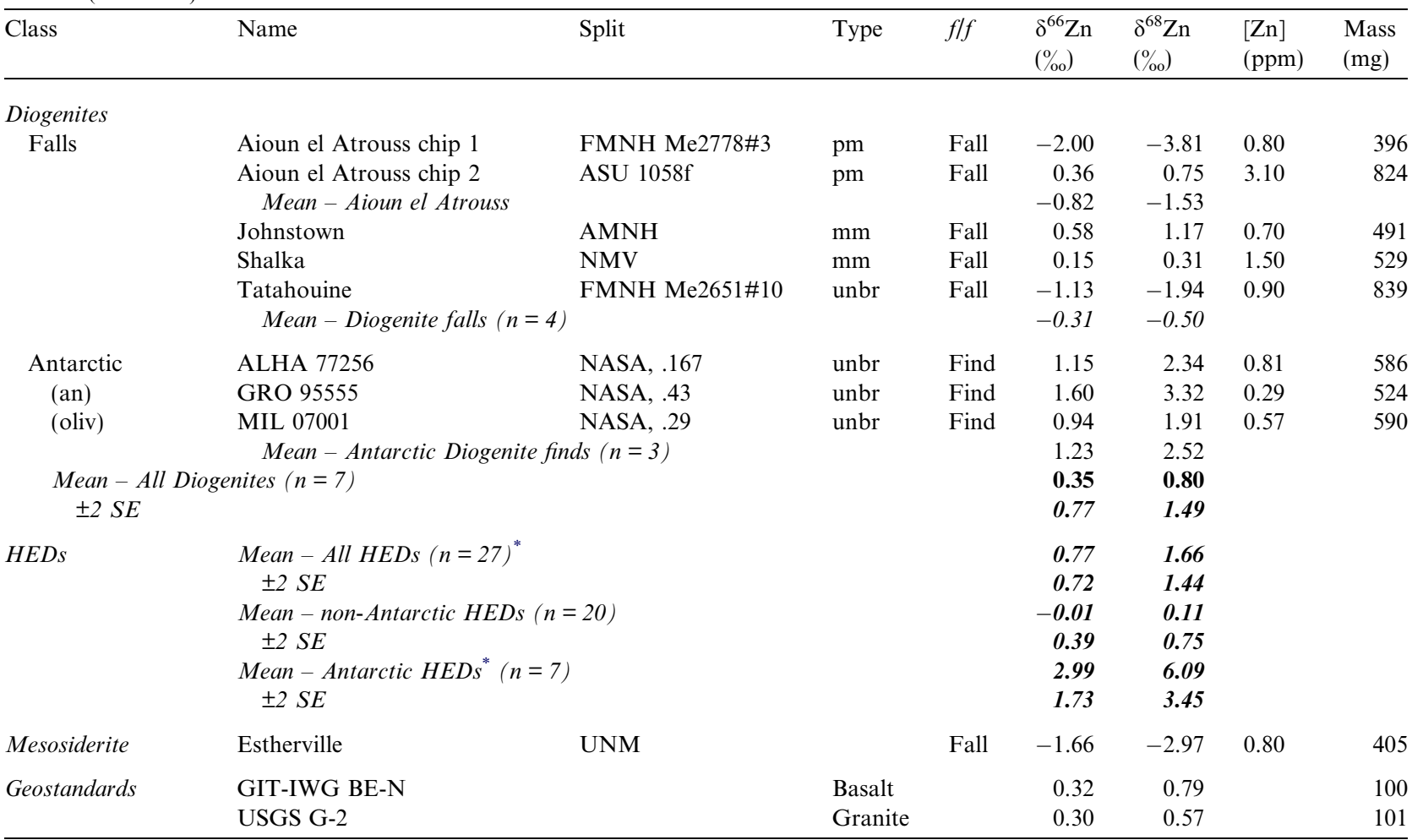

$\delta^{66} \mathrm{Zn}$ and $\delta^{68} \mathrm{Zn}$ measurements in per mil (\%). Zn concentrations in ppm.

Samples were generously provided by the following collections: Meteorite Working Group, NASA, Houston (8); Museum National D'Histoire Naturelle, Paris (MNHN, seven samples including the powders prepared by Barrat); Arizona State University (ASU, 3); Naturhistorisches Museum, Vienna (NMV, 3); Natural History Museum, London (NHM) (BM, 2); Field Museum of Natural History, Chicago (FMNH, 2); Western Australian Museum, Perth (WAM, 2); University of New Mexico (UNM, 2); Smithsonian Institution, Washington D.C. (USNM, 1); American Museum of Natural History, New York (AMNH, 1).

* PCA 82502 excluded from Eucrite and HED means.

eucrites from $-1.76 \%$ to $+1.67 \%$, with a mean of $\delta^{66} \mathrm{Zn}=0.00 \pm 0.58 \%$ o (2 se); howardites from $-0.43 \%$ to $+1.38 \%$, with a mean of $\delta^{66} \mathrm{Zn}=+0.26 \pm 0.62 \%$ ( $\left.2 \mathrm{se}\right)$; non-Antarctic diogenites from $-2.00 \%$ to $+0.58 \%$, with a mean of $\delta^{66} \mathrm{Zn}=-0.31 \pm 0.80 \%$ o (2 se). The mean $\delta^{66} \mathrm{Zn}$ for all of the non-Antarctic HEDs studied is $-0.01 \pm 0.39 \%$ ( $2 \mathrm{se}$ ). The Antarctic values are significantly heavier, with one notable exception (PCA 82502, discussed below): the Antarctic eucrites (excluding PCA 82502) have $\delta^{66} \mathrm{Zn}$ from $+1.63 \%$ to $+6.22 \%$, with a mean of $4.31 \pm 2.23 \%$ o (2 se), while the Antarctic diogenites have $\delta^{66} \mathrm{Zn}$ from $+0.94 \%$ to $+1.60 \%$, with a mean of $1.23 \pm 0.39 \%$ o $(2 \mathrm{se})$. The three separated clasts and two separated matrix samples of Juvinas show some limited isotopic variability with $0.30<\delta^{66} \mathrm{Zn}<0.57$. The mesosiderite Estherville is isotopically light with $\delta^{66} \mathrm{Zn}=-1.66 \pm$ $0.09 \%$. Fig. 1 also gives the results for $\delta^{68} \mathrm{Zn}$, which are consistent with the $\delta^{66} \mathrm{Zn}$ values as the results of massdependent fractionation.

The two terrestrial geostandards analyzed in the present study, the basalt BE-N $\left(\delta^{66} \mathrm{Zn}=0.32\right)$ and the granite $\mathrm{G}-2$ $\left(\delta^{66} \mathrm{Zn}=0.30\right)$ show typical terrestrial isotopic composition $\left(\delta^{66} \mathrm{Zn}=0.20-0.60\right)$ reported by Albarède (2004), Ben Othman et al. (2006), and Cloquet et al. (2008).
In Fig. 2, the $\delta^{66} \mathrm{Zn}$ ranges for the HEDs in this study and literature values for other groups of meteorites, terrestrial samples and lunar samples are shown for comparison. The non-Antarctic HED mean is similar and the range only slightly broader than corresponding values for ordinary and carbonaceous chondrites. The unbrecciated Antarctic HEDs are heavier and range from $\delta^{66} \mathrm{Zn}=+0.94 \%$ to $+6.22 \%$. By contrast, the range for terrestrial igneous rocks is quite narrow, with $\delta^{66} \mathrm{Zn}=+0.2 \%$ to $+0.6 \%$ (Ben Othman et al., 2006; Cloquet et al., 2008, and this study); while the range for enstatite meteorites is very broad, from $-7.08 \%$ for aubrites to $+7.35 \%$ for EL chondrites (Paniello et al., 2009; Moynier et al., 2011). Nevertheless, with $\delta^{66} \mathrm{Zn}=-7.75 \%$, PCA 82502 lies outside this range as the most extreme $\mathrm{Zn}$ fractionation reported to date.

Fig. 3 shows the $\delta^{66} \mathrm{Zn}$ values as a function of zinc concentration. In general there is no clear relationship among these samples, although the plot does highlight the very low zinc concentrations in most of the samples. Considering only the Antarctic meteorites, there is a definite trend of higher $\delta^{66} \mathrm{Zn}$ with lower concentration $\left(R^{2}=0.8271\right)$. This would be consistent with mass-dependent evaporation with preferential loss of lighter isotopes. 


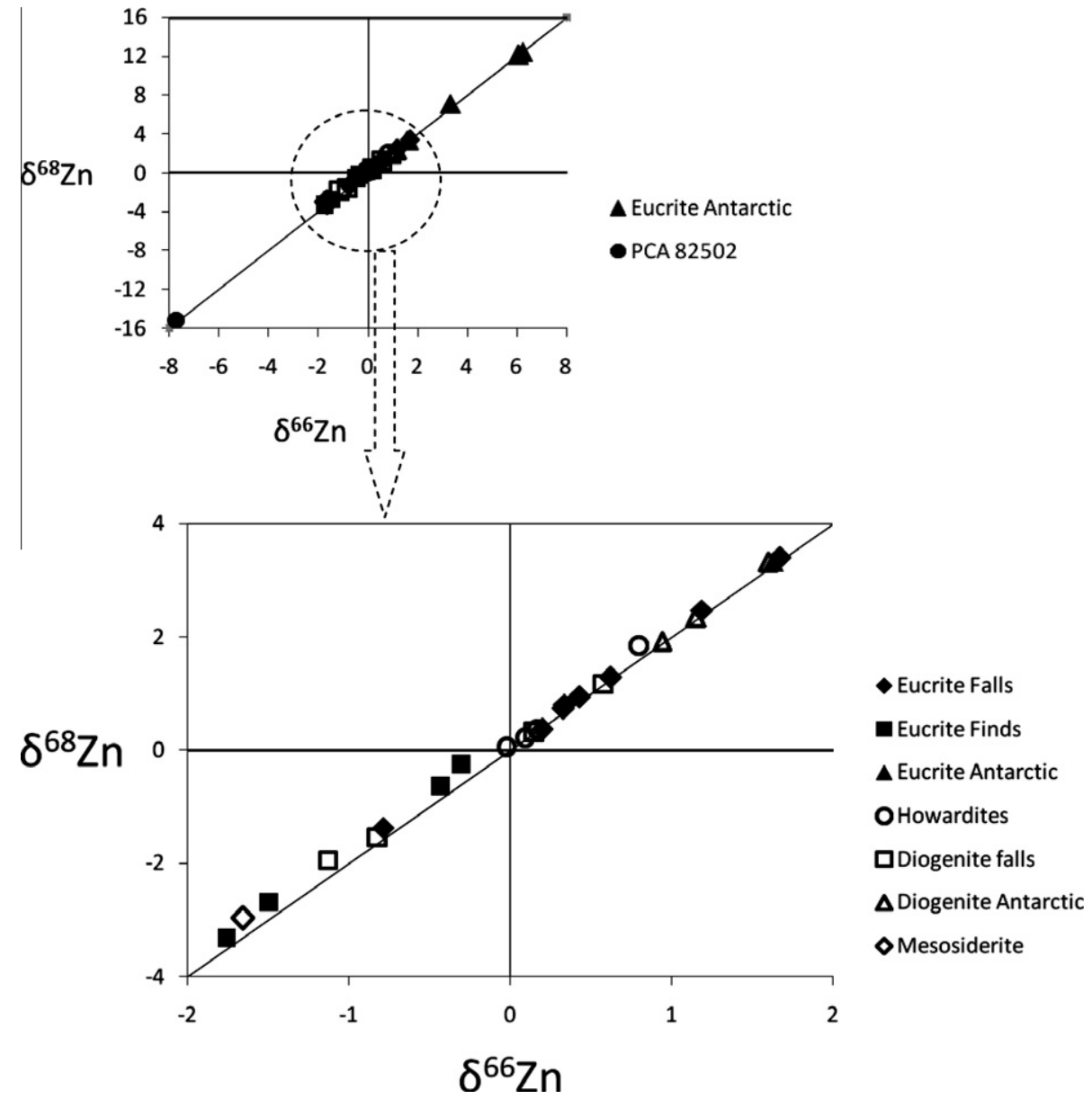

Fig. 1. Three-isotope plot of $\mathrm{Zn}$ isotopic measurements in HED meteorites and one mesosiderite. With the exceptions of PCA 82502 (more negative) and the other Antarctic eucrites (more positive), all $\delta^{66} \mathrm{Zn}$ values fall between $0 \pm 2 \%$. All data plot on the mass-dependent fractionation line of slope 1.978 .

\section{DISCUSSION}

\subsection{Isotopic variation within an individual meteorite}

Some of the samples showed significant $\mathrm{Zn}$ isotopic heterogeneity within the same small chip from the meteorite. For example, two analyses on different fragments of the chip of howardite Kapoeta gave $\delta^{66} \mathrm{Zn}$ values of $-0.43 \%$ and $+0.38 \%$. Two analyses on different fragments of the eucrite Pasamonte chip from ASU gave $\delta^{66} \mathrm{Zn}$ values of $-0.81 \%$ and $+0.05 \%$. These variations occur in fragments of the rock that are physically separated by only a few millimeters. Variations were also seen in different chips from the same meteorite. Chips obtained from two different museums gave significantly different values for the eucrites Pasamonte $(+1.35$ (New Mexico) vs. $+0.05 \%$ and $-0.81 \%$ $(\mathrm{ASU})$ ) and Sioux County $(-0.73$ (ASU) vs. $+\sim 1.0 \%$ $(\mathrm{NHM})$ ), and for the diogenite Aioun el Atrouss (-2.0 (FMNH) vs. $+0.36 \%$ (ASU)). It is not known how far apart these chips were on the original meteorite, but it was likely on the order of centimeters based on the sizes of the meteorites at the time of recovery.
This small-scale heterogeneity is best explained by the brecciation process present in almost all of these samples. Some of the samples are polymict and contain multiple lithologies; further, the single-lithology monomict samples may or may not represent the bulk. The chips prepared for analysis contain variable amounts of matrix, clast, and inclusion contaminants; thus, small-scale variability should be expected in these measurements.

Less small-scale variability would be expected if larger samples were analyzed, since the homogenized powder essentially gives the average of the total mass. This concept was tested using larger $(\sim 2 \mathrm{~g})$ samples from the monomict eucrite fall Juvinas. Two matrix samples had the same $\delta^{66} \mathrm{Zn}$, within error $(0.30$ and 0.37$)$, while three large clasts showed small heterogeneity $(0.39,0.57$ and 0.31$)$. This resembles a chondritic $\mathrm{Zn}$ isotopic composition (see below).

Zinc isotopic heterogeneity has been previously reported in chondrites and in iron meteorites by Luck et al. (2005) and by Ghidan and Loss (2011). Ghosh and McSween (1998) proposed a model for Vesta of a melted center with an unmelted outer shell which would be expected to retain some isotopic heterogeneity. This idea was further sup- 


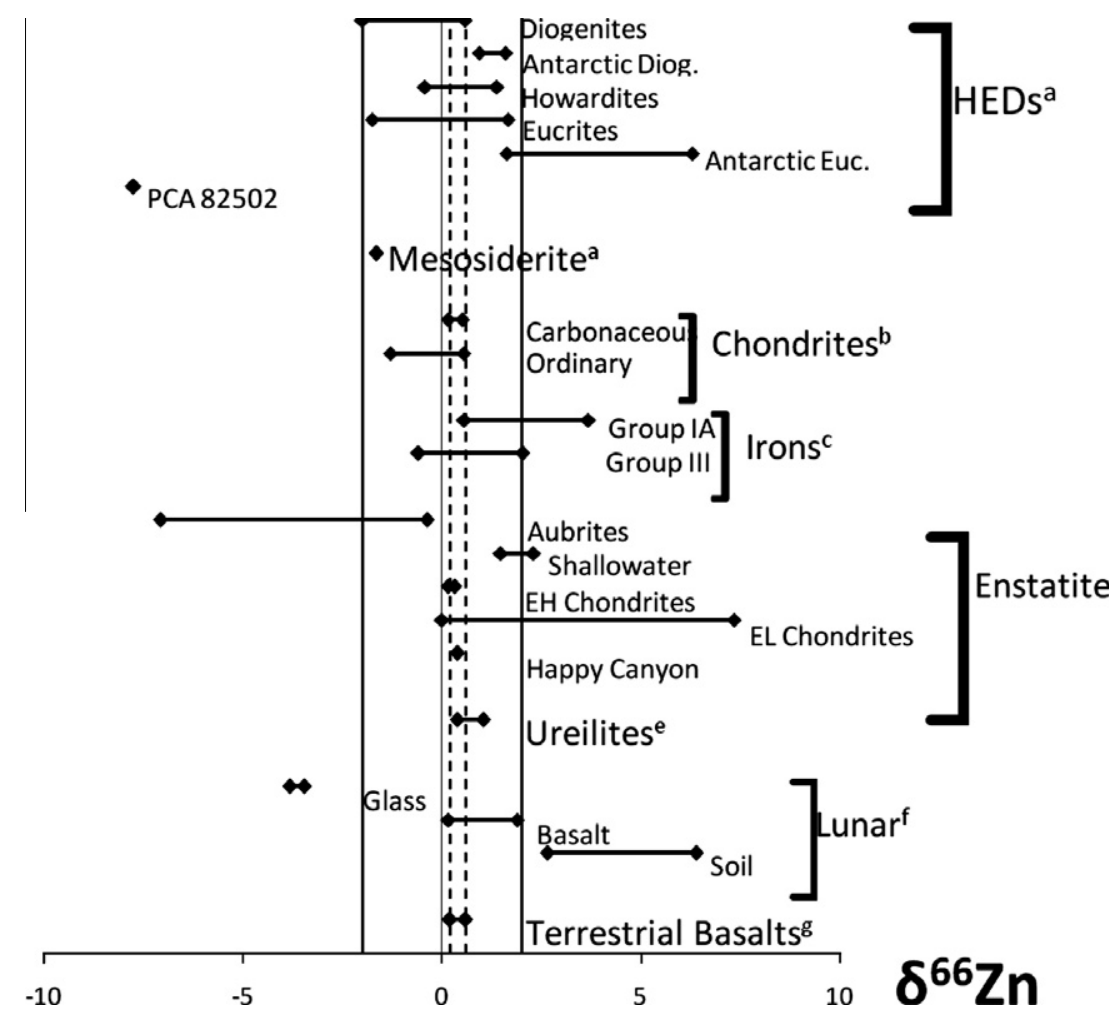

Fig. 2. $\delta^{66} \mathrm{Zn}$ ranges for different group of meteorites, lunar samples and terrestrial igneous rocks. Vertical broken lines show the range for terrestrial basalts, $+0.2 \%$ to $+0.6 \%$; solid lines represent the heterogeneity range of non-Antarctic HEDs, $0 \pm 2 \%$. References: a - this work; b- Luck et al., 2005; Moynier et al., 2007; c - Luck et al., 2005 ; d - Paniello et al., 2009; Moynier et al., 2010; e - Moynier et al., 2010; fMoynier et al., 2006; Herzog et al., 2009; g - Ben Othman et al., 2003, 2006; Cloquet et al., 2008; this study.

ported by Wiechert et al. (2004), who reported heterogeneous oxygen isotope measurements in HEDs consistent with a very rapid early history of large-scale, incomplete mixing on Vesta. The $\mathrm{Zn}$ isotopic heterogeneity found in our study fits with both of these models if the $\mathrm{Zn}$ was initially isotopically heterogeneous in Vesta or if some isotopic fractionation occurred early in Vesta history.

The low zinc concentration in these rocks (about $1 \mathrm{ppm}$ for most HEDs) also contributes to the measured heterogeneity. Very small inclusions rich in light or heavy isotopes of zinc could significantly alter the isotopic composition of these small chips. For example, carbonaceous chondrite xenoliths have been reported in Kapoeta (Wilkening, 1973) and Pasamonte (Metzler et al., 1995) and could alter the measured $\mathrm{Zn}$ ratios; these may have been introduced by an impactor. CM- and CR- like clasts, ranging in size from $25 \mu \mathrm{m}$ to $5 \mathrm{~mm}$, have been reported in HEDs by Buchanan et al. (2009); their wide distribution in the breccias suggested efficient energetic mixing of impactors as the most likely source. Since the HEDs are almost all monomict or polymict breccias, there is also a possibility that the measured fractionation is influenced by the isotopic makeup of the matrix, which contains higher levels of contaminant debris than the clast minerals, rather than the primary minerals themselves.

By contrast, terrestrial basalts from a variety of magmatic settings show a very narrow range of +0.2 $0<\delta^{66} \mathrm{Zn}<+0.60$ (Ben Othman et al., 2003, 2006; Albarède, 2004; Cloquet et al., 2008; Herzog et al., 2009; this study) which suggest that $\mathrm{Zn}$ isotopes are homogeneously well distributed within the Earth's mantle, and that igneous processes do not lead to subsequent $\mathrm{Zn}$ isotopic fractionation. This may be related to the higher zinc concentrations in terrestrial igneous rocks $([\mathrm{Zn}]=50-100 \mathrm{ppm}$; Lodders and Fegley, 1998), or a greater homogenation of kilogram-sized terrestrial samples used as standards, but it may also indicate a significant difference in the formation history of the two planetary bodies. Earth is substantially larger than Vesta, and would have required a much longer cooling time, with a corresponding greater degree of convection and equilibration than Vesta. Thus, Earth would also be expected to have greater isotopic homogeneity than Vesta, as described above for $\mathrm{Zn}$ isotopes.

\subsection{Unbrecciated Antarctic samples \& weathering}

Of the nearly 600 eucrites currently recognised with official names, there are 30 meteorites (about $5 \%$ ) that are classified as unbrecciated eucrites, and all of these are Antarctic finds. Our $\delta^{66} \mathrm{Zn}$ measurements in five of these meteorites were striking; four were isotopically quite heavy (mean, $+4.31 \%$ ), while one was anomalously light (PCA 82502, discussed below). These unbrecciated specimens are most likely samples of the original, early Vestan crust, which were expelled by early impacts and thus spared from further impacts that would have led to their brecciation. The three unbrecciated Antarctic diogenites studied were also isotopically hea- 

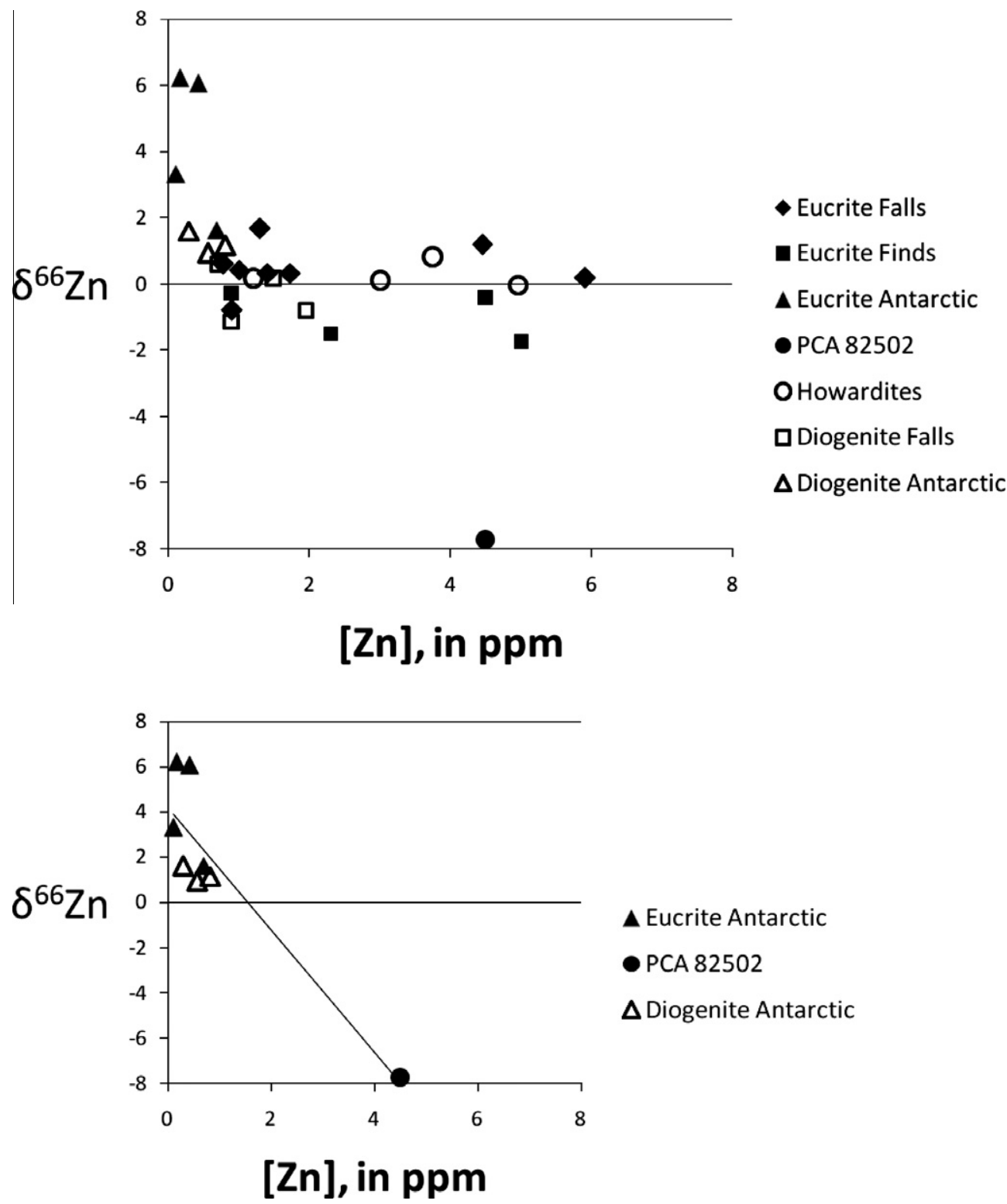

Fig. 3. $\delta^{66} \mathrm{Zn}$ values as a function of $\mathrm{Zn}$ concentration. Overall, no correlation was found (upper plot); but a loose correlation $\left(\mathrm{R}^{2}=0.8271\right)$ was seen among the Antarctic meteorite samples (lower plot).

vier than the other diogenites, but to a lesser degree. These likely formed deeper in the crust or upper mantle, where volatization of $\mathrm{Zn}$ would occur to a lesser extent, making them isotopically heavy but not as extreme as the eucrites.

The role of weathering on the measured $\mathrm{Zn}$ fractionation is unclear, but is likely limited. Biswas et al. (1980) studied trace elements in four Antarctic meteorites, and found that there was limited contamination or leaching of trace elements at the periphery of the meteorites, but interior samples gave reasonably normal values for their respective subgroups. Kallemeyn et al. (1993) compared chondrite Antarctic finds with falls, and found "concentration ranges and median values of two chalcophile elements, Se and $\mathrm{Zn}$, are nearly identical between the Antarctic $\mathrm{H}$ chondrites and H falls." Wang et al. (1992) studied a large suite of chondrites, HEDs and lunar meteorites, and found that although REE composition may have been altered in some eucrites, there was no evidence for labile trace element transport into or out of eucrites of weathering grade A to B (our five eucrites include four A and one B; our three diogenites are all A/B). Carbonaceous chondrites and lunar meteorites were also essentially unaltered. Wang and Lipschutz (1995) also found no weathering effects in $\mathrm{Zn}$ and other trace elements for Antarctic ureilites. Mittlefehldt and Lindstrom (1991) found significant REE depletion in a group of abnormal Antarctic eucrites, but trace elements such as $\mathrm{Zn}$ were not reported.

We note that there are no known terrestrial materials with the extreme fractionations seen in these Antarctic meteorites (either very heavy, like four in this study, or very light, like PCA 82502), so this degree of $\mathrm{Zn}$ fractionation cannot be explained by local contamination. We conclude that weather- 
ing effects in our Antarctic meteorites, if any, are likely small $(<1 \%)$ and thus cannot possibly explain the large differences in $\mathrm{Zn}$ fractionation seen between the unbrecciated Antarctic samples and the brecciated falls and finds.

\subsection{Falls vs. finds}

There was a small difference in $\delta^{66} \mathrm{Zn}$ values based on the mechanism of recovery of the meteorite. For the eucrites, the $\delta^{66} \mathrm{Zn}$ for the eight observed falls averaged $+0.50 \pm 0.51 \%$ o ( $2 \mathrm{se}$ ), while the four non-Antarctic finds averaged $-1.00 \pm 1.01 \%$. This finding may simply be a result of sampling, as all of the HEDs seem to be scattered between $\delta^{66} \mathrm{Zn}=0 \pm 2 \%$. This observation could also suggest that the terrestrial non-Antarctic weathering process preferentially removes heavy isotopes from the meteorite. This direction of isotopic fractionation during weathering was also reported by Luck et al. (2005) for $\mathrm{Zn}$ isotopes in undifferentiated ordinary chondrites: an $\mathrm{H} 3.7$ find was $0.40 \%$ lighter (for $\delta^{66} \mathrm{Zn}$ ) than an $\mathrm{H} 3.8$ fall, while an L3.6 find was $1.27 \%$ lighter than an L3.6 fall. All of the howardites and diogenites in the present study were falls.

\subsection{Chondritic origin for Vesta and the origin of the elemental depletion of HEDs}

The range of $\delta^{66} \mathrm{Zn}$ observed in the three large clasts and two matrix samples from Juvinas $(0.30-0.57 \%$ ) and the average value close to zero $(-0.01 \pm 0.39$ ( $2 \mathrm{se})$ for all non-Antarctic HED samples) suggest a chondritic $\mathrm{Zn}$ isotopic composition for Vesta. Individual fragments of brecciated HEDs exhibit a small scale isotopic heterogeneity. The isotopic variation measured in lunar soils (Moynier et al., 2006) suggests that the heterogeneity observed in brecciated eucrites is the result of the brecciation processes. Zinc isotopes are redistributed at the surface of 4-Vesta, presumably by evaporative processes. Under this scenario, the volatilized isotopically light zinc may have left the molten body's surface, then remained in a primordial atmosphere and was later recondensed back into the asteroid, initially at the surface. The result would be a heterogeneous Vesta surface with some isotopically light and isotopically heavy regions. Subsequent impacts would pulverize these rocks to varying degrees, and result in brecciation such as seen in the meteorites that reach the Earth. The depletion of moderately volatile elements such as $\mathrm{Zn}$ would have to have occurred prior to this process.

The average $\mathrm{Zn}$ fractionation for this group of HED meteorites was approximately zero, similar to ordinary chondrites (Luck et al., 2005; Moynier et al., 2007; Ghidan and Loss, 2011). Considering only the eucrite falls, the average $\delta^{66} \mathrm{Zn}$ value of $+0.50 \pm 0.51 \%$ was identical to the CI chondrites reported by Luck et al. (2005), who found mean $\delta^{66} \mathrm{Zn}=+0.49 \%$ and $+0.47 \%$ for Orgueil and Ivuna, respectively. In addition, large clasts and matrix samples from Juvinas show a fairly homogeneous $\mathrm{Zn}$ isotopic composition of $0.33 \pm 0.13 \%$, similar to chondritic values.

Thus, Vesta may have originally accreted from chondritic material. However, the typical chondrite $\mathrm{Zn}$ abundance is about 50 ppm (e.g., Luck et al., 2005), while the range of $\mathrm{Zn}$ in HEDs is about 1-7 ppm, so the HEDs must have lost $86-98 \%$ of their $\mathrm{Zn}$ without any isotopic fractionation. The unbrecciated samples allow us to propose an explanation for these findings. The data fit with a model in which Vesta originally accreted from material with a chondritic $\mathrm{Zn}$ content; Vesta then lost by evaporation most $(>90 \%)$ of its volatiles (e.g. Zn) early in its history as it slowly cooled. This left a surface comprised of unbrecciated, isotopically heavy eucritic material, with a layer of diogenites below that was also heavy, but less so. Early impacts ejected the unbrecciated meteorites that were found in this study to be enriched in heavy $\mathrm{Zn}$ isotopes, before they could become brecciated. Additional impacts, likely from largely chondritic material, led to the brecciation of the surface as well as the addition of $\mathrm{Zn}$ with a chondritic isotopic composition. This hypothesis is consistent with Scott et al. (2009b), who note that unbrecciated eucrites show no shock features, unlike most brecciated ones.

A Rayleigh evaporation model can be used to further test this hypothesis, using the equation

$\delta^{66} \mathrm{Zn}=\left(\delta^{66} \mathrm{Zn}_{0}+1000\right) f^{(\alpha-1)}-10^{3}$

where $f=[\mathrm{Zn}] /[\mathrm{Zn}]_{0}$ and $\alpha=(64 / 66)^{0.5}$ based on the masses of the species. Starting with chondritic values from Luck et al. (2005) of $[\mathrm{Zn}]_{0}=50 \mathrm{ppm}$ and $\delta^{66} \mathrm{Zn}_{0}=+0.50 \%$, using (1), we find that the expected $\mathrm{Zn}$ fractionation for pure Rayleigh evaporation to a final $[\mathrm{Zn}]$ of $1 \mathrm{ppm}$ gives $\delta^{66} \mathrm{Zn}=$ $+62.1 \%$. The measured $\delta^{66} \mathrm{Zn}$ values reported in this study are all substantially lower than this, implying that significant mixing must have occurred after evaporation. This supports the model for evaporative volatile loss proposed above.

A comparison may also be made with the surface of the Moon. Like Vesta, the lunar surface has been largely depleted of its $\mathrm{Zn}$, with [Zn] of 5-20 ppm in most samples. The lunar basalts show $\mathrm{Zn}$ fractionation that is largely chondritic, while the soil, which has been substantially gardened by impacts, is isotopically heavy (Moynier et al., 2006; Herzog et al., 2009) (Fig. 2). Micrometeorite vaporization and sputtering were proposed as mechanisms by which the regolith might become isotopically heavier; but evaporation of light isotopes and $\mathrm{Zn}$ contributions from chondritic impactors, as proposed for Vesta herein, may also have played a role on the Moon.

Schönbächler et al. (2008) found a similar depletion without fractionation of another moderately volatile element, cadmium, in three eucrites, Béréba, Bouvante, and Juvinas. The cadmium isotopic composition of these eucrites was chondritic, within error $(\sim 0.4 \%)$, and the concentration was depleted by a factor of $\sim 600$ to the $\sim 1 \mathrm{ppb}$ level compared to $\mathrm{CI}$ chondrites. Wombacher et al. (2008) had similar results for ${ }^{114} \mathrm{Cd} /{ }^{110} \mathrm{Cd}$ ratios in two monomict eucritic breccias. They also concluded that the primary volatile element depletion of the inner solar system did not involve kinetic Rayleigh evaporation or condensation. Moynier et al. (2011) also reported $\mathrm{Zn}$ depletion without fractionation in enstatite chondrites and aubrites, again concluding that the findings were not due to evaporative/condensation processes. It is possible that Vesta's original depletion in $\mathrm{Zn}$ may have also been nonevaporative, but the heavy unbrecciated Antarctic samples 
support a mass-dependent fractionation process such as volatization.

If we assume that 4-Vesta accreted from chondritic material, then most of the $\mathrm{Zn}$ was subsequently removed or stored in phases not sampled by HEDs, with no associated isotopic fractionation, early in 4-Vesta history. One possibility includes the sequestration of $\mathrm{Zn}$ into spinel, as suggested by Chikami et al. (1997), which would have happened at high temperature with little or no associated isotopic fractionation and is consistent with the depletion of $\mathrm{Cu}$, $\mathrm{Zn}$, and $\mathrm{Cd}$ in these meteorites. Another proposed phase is the sulfides (troilite), but studies have found little or no troilite in the HEDs, and little or no $\mathrm{Zn}$ in the troilite that is found (Nishimura and Sandell, 1964; Chikami et al., 1997). Another alternative would be that the chondritic material that formed Vesta lost most of its $\mathrm{Zn}$ in a non-fractionating process prior to or during accretion. These speculations regarding zinc-containing phases cannot be resolved with the data collected in this study.

\subsection{PCA 82502}

The Antarctic eucrite Pecora Escarpment (PCA) 82502 was extremely light in $\mathrm{Zn}$ isotopes compared with the other HEDs, with $\delta^{66} \mathrm{Zn}$ of $-7.75 \%$, a value that represents the most extreme $\mathrm{Zn}$ fractionation in the solar system reported to date. It is an unbrecciated eucrite (Grossman, 1994; Bogard and Garrison, 2003), although Bermingham et al. (2008) describe it as consisting of rounded basaltic clasts surrounded by a fine-grained matrix. These authors suggest this meteorite is unequilibrated, and probably erupted as a surface flow. Bermingham et al. (2008) report that PCA 82502 has a light REE-depleted pattern with a positive europium anomaly, as well as other incompatible trace element depletions, and they suggest that this meteorite (and three others in their study) should be considered a "new variety of non-cumulate basaltic eucrite." It has a weathering grade of "A," and its initial write-up indicated that essentially no weathering was observed. This suggests that the extreme $\mathrm{Zn}$ isotopic fractionation measured was not significantly affected by its Antarctic exposure.

PCA 82502 is unusual in other ways. Jovanovic and Reed (1988) found that it had a higher $\mathrm{Hg}$ equilibration temperature than the other eucrites tested, and proposed that it could be a rapidly chilled magma representing the original crust that has not undergone impact melting and burial. Greenwood et al. (2009) noted that PCA 82502 has a $\Delta^{17} \mathrm{O}$ value enough outside the expected range that its origin on Vesta can be regarded as uncertain (along with Pasamonte and four others). Herpers et al. (1995) found this meteorite to have an extremely low ${ }^{10} \mathrm{Be}$ activity, implying, at minimum, a "complex exposure history." These peculiarities, and especially the extremely negative $\mathrm{Zn}$ isotopic fractionation, lead us to conclude that PCA 82502 most likely originated from a different parent body, and not from 4-Vesta.

\section{CONCLUSION}

The isotopic composition of 20 non-Antarctic HEDs show an average $\delta^{66} \mathrm{Zn}=-0.01 \pm 0.39 \%$ ( 2 se), with a range of about $0 \pm 2 \%$. This isotopic variation among and within HED meteorites is much larger than anything observed in terrestrial igneous rocks from various magmatic settings and suggest that the HED parent body (4 Vesta) retained an initial heterogeneity that has been lost on Earth, or acquired heterogeneity later from impact contributions. This is probably due to a weaker and much shorter geological activity on Vesta than on Earth. The unbrecciated Antarctic HEDs are isotopically heavy, suggesting that Vesta may have lost most of its zinc (and other volatiles) early in its accretion history, and impacts led to the creation of isotopically heavy Vestoids. Additional impacts led to impact gardening and brecciation, with major contributions to the surface zinc delivered by chondritic impactors.

The unbrecciated eucrite PCA 82502 is a unique sample which has the lightest $\mathrm{Zn}$ isotopic composition measured so far in any solar system materials $\left(\delta^{66} \mathrm{Zn}=-7.75 \%\right.$ ). This dramatic enrichment in light isotopes of PCA 82502 together with its unusual oxygen isotopic composition suggest that this sample has a very different history than the other HED meteorites. PCA 82502 is most likely derived from a completely different parent body.

\section{ACKNOWLEDGMENTS}

The authors thank David W. Mittlefehldt, two anonymous reviewers, and Associate Editor Trevor Ireland for their thorough and constructive reviews and suggestions for the final manuscript. We thank Francis Alberede for the generous access to the Nu Plasma mass spectrometer at ENS-Lyon.

We also thank Cecilia Satterwhite and Kevin Righter (MWGNASA, Houston), Brigitte Zanda (MNHN-Paris), Laurence Garvie and Meenakshi Wadhwa (ASU, Tempe), Franz Brandstatter (Vienna), Caroline Smith (NHM-London), James Holstein and Clarita Nunez (Field Museum, Chicago), Alex Bevan (W. Australian Museum), Jim Karner and Carl Agee (U. New Mexico, Albuquerque), Tim McCoy (Smithsonian Institution, Washington DC), and Joseph Boesenburg and Denton Ebel (AMNH, New York) who generously supplied the meteorite samples and their support for this work.

\section{REFERENCES}

Albarède F. (2004) The stable isotope geochemistry of copper and zinc. Rev. Mineral. Geochem. 55, 409-427.

Albarède F. et al. (2007) Isotope fractionation during impact: Earth versus the moon. Meteor. Planet. Sci. 42, A11.

Asphaug E. (1997) Impact origin of the Vesta family. Meteor. Planet. Sci. 32, 965-980.

Barrat J. A. (2004) Determination of the parental magmas of HED cumulates: the effects of interstitial melts. Meteor. Planet. Sci. 39, 1767-1779.

Barrat J. A., Blichert-Toft J., Gillet P. and Keller F. (2000) The differentiation of eucrites: the role of in situ crystallization. Meteor. Planet. Sci. 35, 1087-1100.

Barrat J. A., Yamaguchi A., Greenwood R. C., Bohn M., Cotten J., Benoit M. and Franchi A. (2007) The Stannern trend eucrites: contamination of Main-Group eucritic magmas by crustal partial melts. Geochim. Cosmochim. Acta 71, 4108-4124.

Barrat J. A., Yamaguchi A., Greenwood R. C., Benoit M., Cotten J., Bohn M. and Franchi I. A. (2008) Geochemistry of 
diogenites: still more diversity in their parental melts. Meteor. Planet. Sci. 43, 1759-1775.

Barrat J. A., Jambon A., Bohn M., Blichert-Toft J., Sautter V., Gopel C., Boudouma O. and Keller F. (2003) Petrology and geochemistry of the unbrecciated eucrite North West Africa 1240 (NWA 1240): an HED parent body impact melt. Geochim. Cosmochim. Acta 67, 3959-3970.

Barrat J. A., Yamaguchi A., Greenwood R. C., Bollinger C., Bohn M., Cotten J. and Franchi I.A. (2009a) Geochemistry of HED cumulates: a synthesis. 72nd MetSoc meeting, \#5151.

Barrat J. A., Bohn M., Gillet P. and Yamaguchi A. (2009b) Evidence for K-rich terranes on Vesta from impact spherules. Meteor. Planet. Sci. 44, 359-374.

Barrat J. A., Yamaguchi A., Zanda B., Bollinger C. and Bohn M. (2010) Relative chronology of crust formation on asteroid Vesta: insights from the geochemistry of diogenites. Geochim. Cosmochim. Acta 74, 6218-6231.

Barrat J. A., Zanda B., Moynier F., Bollinger C., Liorzou C. and Bayon G. (2012) Geochemistry of CI chondrites: major and trace elements, and $\mathrm{Cu}$ and $\mathrm{Zn}$ isotopes. Geochim. Cosmochim. Acta 83, 79-92.

Ben Othman D., Luck J. M., Tchalikian A. and Albarède F. (2003) $\mathrm{Cu}-\mathrm{Zn}$ isotope systematics in terrestrial basalts. Geophys. Res. Abs. 5, \#09669.

Ben Othman D., Luck J. M., Bodinier J. L., Arndt N. T. and Albarède F. (2006) Cu-Zn isotopic variations in the Earth's mantle. Geochim. Cosmochim. Acta Supp. 70, A46.

Bermingham K. R., Norman M. D., Christy A. G. and Arculus R. J. (2008) A new variety of eucrite? Clues to early differentiation of igneous asteroids. LPSC 39, \#1225.

Binzel R. P. and Xu S. (1993) Chips off asteroid 4 Vesta: evidence for the parent body of basaltic achondrite meteorites. Science $\mathbf{2 6 0}$, 186-191.

Biswas S., Ngo H. T. and Lipschutz M. E. (1980) Trace element contents of selected Antarctic meteorites. I - Weathering effects and ALH A77005, A77257, A77278 and A 77299. Zeitschrift fuer Naturforschung, Teil 35, 191-196.

Bogard D. D. and Garrison D. H. (2003) ${ }^{39} \mathrm{Ar}-{ }^{40} \mathrm{Ar}$ ages of eucrites and thermal history of asteroid 4 Vesta. Meteor. Planet. Sci. 38, 669-710.

Buchanan P. C., Zolensky M. E., Greenwood R. C. and Franchi I. A. (2009) Foreign materials in polymict breccias from Vesta. 72nd MetSoc meeting, \#5180.

Burbine T. H., Buchanan P. C., Binzel R. P., Bus S. J., Hiroi T., Hinrichs J. L., Meibom A. and McCoy T. J. (2001) Vesta, Vestoids, and the howardite, eucrite, diogenite group: Relationships and the origin of spectral differences. Meteor. Plan. Sci. 36, 761-781.

Chikami J., Takeda H., Yugami K., Mikouchi T. and Miyamoto M. (1997) $\mathrm{Zn}$ abundance in coexisting troilite and spinel in achondrites: remnant indicative of the primitive source materials. LPS 28, \#1490.

Clayton R. N. and Mayeda T. K. (1996) Oxygen isotope studies of achondrites. Geochim. Cosmochim. Acta 60, 19992017.

Cloquet C., Carignan J., Lehmann M. F. and Vanhaecke F. (2008) Variation in the isotopic composition in the natural environment and the use of zinc isotopes in the biosciences: a review. Anal. Bioanal. Chem. 390, 451-463.

Ghidan O. Y. and Loss R. D. (2011) Isotope fractrionation and concentration measurements of $\mathrm{Zn}$ in meteorites determined by the double spike, IDMS-TIMS techniques. Meteor. Plan. Sci. 46, 830-842.

Ghosh A. and McSween H. Y. (1998) A thermal model for the differentiation of asteroid 4 Vesta, based on radiogenic heating. Icarus 134, 187-206.
Greenwood R. C., Franchi I. A., Jambon A. and Buchanan P. C. (2005) Widespread magma oceans on asteroidal bodies in the early Solar System. Nature 435, 916-918.

Greenwood R. C., Franchi I. A., Jambon A., Barrat J. A. and Burbine T. H. (2006) Oxygen isotope variation in stony-iron meteorites. Science 313, 1763-1765.

Greenwood R. C., Franchi I. A., Scott E. R. D., Barrat J. A. and Norman M. (2009) Oxygen isotope variation in the HEDs: how homogenous is Vesta? 72nd Met. Soc. meeting, \#5436 (abstr.).

Grossman J. N. (1994) Meteoritical Bulletin, No. 76. Meteoritics 29, 100-143.

Herpers U., Vogt S., Bremer K., Hofmann H. J., Suter M., Wieler R., Lange H.-J. and Miche R. (1995) Cosmogenic nuclides in differentiated Antarctic meteorites: measurements and model calculations. Planet. Space Sci. 43, 545-556.

Herzog G. F., Moynier F., Albarède F. and Berezhnoy A. (2009) Isotopic and elemental abundances of copper and zinc in lunar samples, Zagami, Pele's hairs, and a terrestrial basalt. Geochim. Cosmochim. Acta 73, 5884-5904.

Hewins R. H. and Newsom H. E. (1988) Igneous activity in the early solar system. In Meteorites and The Early Solar System (eds. J. F. Kerridge and M. S. Matthews). Univ. Arizona Press, Tuscon, AZ, pp. 73-101.

Jovanovic S., Reed G. W. (1988) Thermometry of eucritic achondrites. Met.Soc. 278 (abstracts).

Kallemeyn G. W., Krot A. N. and Rubin A. E. (1993) Preliminary compositional comparisons of $\mathrm{H}$-chondrite falls to Antarctic $\mathrm{H}$ chondrite populations. Meteoritics 28, 377.

Kitts K. and Lodders K. (1998) Survey and evaluation of eucrite bulk compositions. Meteor. Plan. Sci. 33, A197-A213.

Lodders K. and Fegley B. (1998) The planetary scientist's companion. Oxford U. Press, New York.

Luck J. M., Ben Othman. D. and Albarède F. (2005) Zn and Cu isotopic variations in chondrites and iron meteorites: early solar nebula reservoirs and parent-body processes. Geochim. Cosmochim. Acta 69, 5351-5363.

Maréchal C. N., Telouk P. and Albarède F. (1999) Precise analysis of copper and zinc isotopic compositions by plasma-source spectrometry. Chem. Geol. 156, 251-273.

McCord T. B., Adams J. B. and Johnson T. V. (1970) Asteroid Vesta: spectral reflectivity and compositional implications. Science 168, 1445-1447.

McSween, Jr., H. J., Mittlefehldt D. W., Beck A. W., Mayne R. G. and McCoy T. J. (2010) HED meteorites and their relationship to the geology of vesta and the Dawn mission. Space Sci. Rev. doi:10.1007/s11214-010-9637-z.

Metzler K., Bobe K. D., Palme H., Spettel B. and Stoffler D. (1995) Thermal and impact metamorphism on the HED parent asteroid. Planet. Space Sci. 43, 499-525.

Mittlefehldt D. W. (1994) The genesis of diogenites and HED parent body petrogenesis. Geochim. Cosmochim. Acta 58, 15371552.

Mittlefehldt D. W. and Lindstrom M. M. (1991) Generation of abnormal trace element abundances in Antarctic eucrites by weathering processes. (Workshop on Differences between Antarctic and non-Antarctic Meteorites, Vienna, Austria, July 27, 28, 1989). Geochim. Cosmochim. Acta 55, 77-87.

Mittlefehldt D. W. and Lindstrom M. M. (2003) Geochemistry of basaltic eucrites, and $\mathrm{Hf}$ and $\mathrm{Ta}$ as petrogenetic indicators for altered Antarctic meteorites. Geochim. Cosmochim. Acta 67, 1911-1935.

Moynier F., Albarède F. and Herzog G. F. (2006) Isotopic composition of zinc, copper, and iron in lunar samples. Geochim. Cosmochim. Acta 70, 6103-6117.

Moynier F., Blichert-Toft J., Telouk P., Luck J. M. and Albarède F. (2007) Comparative stable isotope geochemistry of $\mathrm{Ni}, \mathrm{Cu}$, 
$\mathrm{Zn}$, and $\mathrm{Fe}$ in chondrites and iron meteorites. Geochim. Cosmochim. Acta 71, 4365-4379.

Moynier F., Beck P., Jourdan F., Yin Q.-Z., Reimold U. and Koeberl C. (2009) Isotopic fractionation of zinc in tektites. Earth Planet. Sci. Lett. 277, 482-489.

Moynier F., Beck P., Barrat J.-A., Ferroir T., Paniello R., Telouk P. and Gillet P. (2010) Volatilization induced by impacts recorded in $\mathrm{Zn}$ isotope composition of ureilites. Chem. Geol. 276, 374-379.

Moynier F., Paniello R., Gounelle M., Albarède F., Beck P., Podosek F. and Zanda B. (2011) Nature of volatile depletion and genetic relationships in enstatite chondrites and aubrites inferred from $\mathrm{Zn}$ isotopes. Geochim. Cosmochim. Acta 75, 297397.

Nishimura M. and Sandell E. B. (1964) Zinc in meteorites. Geochim. Cosmochim. Acta 28, 1055-1079.

Nyquist L. E., Takeda H., Bansal B., Shih C. Y., Wiesmann H. and Wooden J. L. (1986) Rb-Sr and Sm-Nd internal isochron ages of a subophitic basalt clast and a matrix sample from the Y75011 eucrite. J. Geophys. Res. 91, 8137-8150.

Paniello R. C., Moynier F., Podosek F. A. and Beck P. (2009) Zn isotopic composition of achondrites and enstatite chondrites. 72nd Met. Soc. meeting, \#3153.

Righter K. and Drake M. J. (1997) A magma ocean on Vesta: core formation and petrogenesis of eucrites and diogenites. Meteor. Planet. Sci 32, 929-944.

Ruzicka A., Snyder G. A. and Taylor L. A. (1997) Vesta as the howardite, eucrite, and diogenite parent body: implications for the size of the core and for large-scale differentiation. Meteor. Planet. Sci 32, 825-840.

Schaefer L. and Fegley B. (2010) Volatile element chemistry during metamorphism of ordinary chondritic material and some of its implications for the composition of asteroids. Icarus 205, 423496.

Schönbächler M., Baker R. G. A., Williams H., Halliday A.N. and Rehkämper M. (2008) The cadmium isotope composition of chondrites and eucrites. 71st Met. Soc. meeting, \#5268.

Scott E. R. D., Greenwood R. C., Franchi I. A. and Sanders I. A. (2009a) Oxygen isotopic constraints on the origin and parent bodies of eucrites, diogenites, and howardites. Geochim. Cosmochim. Acta 73, 5835-5853.

Scott E. R. D., Bogard D. D., Bottke W. F., Taylor G. J., Greenwood R. C., Franchi I. A., Keil K., Moskovitz N. A. and Nesvorny D. (2009b) Impact histories of Vesta and Vestoids inferred from howardites, eucrites, and diogenites. LPSC 40, \#2295.

Shearer C. K., Fowler G. W. and Papike J. J. (1997) Petrogenic models for magmatism on the eucrite parent body: evidence for orthopyroxene in diogenites. Meteor. Planet. Sci. 32, 877-889.

Stolper E. (1977) Experimental petrology of eucrite meteorites. Geochim. Cosmochim. Acta 41, 587-611.

Takeda H. (1979) A layered-crust model of a howardite parent body. Icarus 40, 455-470.
Takeda H. (1997) Mineralogical records of early planetary processes on the howardite, eucrite, diogenite parent body with reference to Vesta. Meteor. Planet. Sci. 32, 841-853.

Takeda H. and Graham A. L. (1991) Degree of equilibration of eucritic pyroxenes and thermal metamorphism of the earliest planetary crust. Meteoritics 26, 129-134.

Thomas P. C., Binzel R. P., Gaffey M. J., Storrs A. D., Wells E. N. and Zellner B. H. (1997) Impact excavation on asteroid 4 Vesta: hubble space telescope results. Science 277, 1492-1495.

Wang M.-S., Xiao X. and Lipschutz M. E. (1992) Alteration of labile trace element concentrations in antarctic meteorites by weathering: a five-year assessment. Meteoritics 27, 303.

Wang M.-S. and Lipschutz M. E. (1995) Volatile trace elements in Antarctic ureilites. Meteoritics 30, 319-324.

Warren P. H. (1997) Magnesium oxide-iron oxide mass balance constraints and a more detailed model for the relationship between eucrites and diogenites. Meteor. Planet Sci. 32, 945963.

Warren P. H. and Jerde E. A. (1987) Composition and origin of Nuevo Laredo trend eucrites. Geochim. Cosmochim. Acta 51, 713-725.

Warren P. H., Kallemeyn G. W., Huber H., Ulff-Møller F. and Choe W. (2009) Siderophile and other geochemical constraints on mixing relationships among HED-meteoritic breccias. Geochim. Cosmochim. Acta 73, 5918-5943.

Wiechert U. A., Halliday A. N., Palme H. and Rumble D. (2004) Oxygen isotope evidence for rapid mixing of the HED meteorite parent body. Earth Planet. Sci. Lett. 221, 373-382.

Wilkening L. L. (1973) Foreign inclusions in stony meteorites-I. Carbonaceous chondrite xenoliths in the Kapoeta howardite. Geochim. Cosmochim. Acta 37, 1985-1989.

Wolf S. F., Wang M.-S. and Lipschutz M. E. (2009) Labile trace elements in basaltic achondrites: can they distinguish between meteorites from the Moon, Mars, and V-type asteroids? Meteor. Planet. Sci. 44, 891-903.

Wombacher F., Rehkamper M., Mezger K., Bischoff A. and Munker C. (2008) Cadmium stable isotope cosmochemistry. Geochim. Cosmochim. Acta 72, 646-667.

Yamaguchi A., Taylor G. J. and Keil K. (1996) Global crustal metamorphism of the eucrite parent body. Icarus 124, 97-112.

Yamaguchi A., Taylor G. J. and Keil K. (1997) Metamorphic history of the eucritic crust of 4 Vesta. J. Geophys. Res. 102, 13381-13386.

Yamaguchi A., Barrat J. A., Greenwood R. C., Shirai N., Okamoto C., Setoyanagi T., Ebihara M., Franchi I. A. and Bohn M. (2009) Crustal partial melting on Vesta: evidence from highly metamorphosed eucrites. Geochim. Cosmochim. Acta 73, $7162-7182$. 